Western University

Scholarship@Western

Aboriginal Policy Research Consortium International (APRCi)

2012

\title{
Socioeconomic disparities in physical health among Aboriginal and Torres Strait Islander children in Western Australia
}

Carrington C.J. Sheperd

Jianghong Li

Stephen R. Zubrick

Follow this and additional works at: https://ir.lib.uwo.ca/aprci

Part of the Other Public Health Commons

Citation of this paper:

Sheperd, Carrington C.J.; Li, Jianghong; and Zubrick, Stephen R., "Socioeconomic disparities in physical health among Aboriginal and Torres Strait Islander children in Western Australia" (2012). Aboriginal Policy Research Consortium International (APRCi). 333.

https://ir.lib.uwo.ca/aprci/333 
This article was downloaded by: [University of Western Ontario]

On: 29 July 2012, At: 06: 30

Publisher: Routledge

Informa Ltd Registered in England and Wales Registered Number: 1072954 Registered

office: Mortimer House, 37-41 Mortimer Street, London W1T 3J H, UK

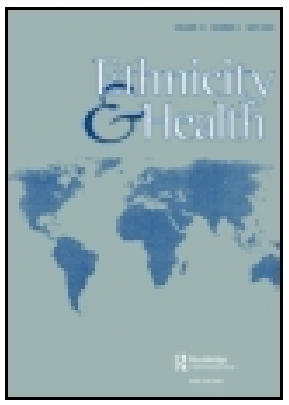

\section{Ethnicity \& Health}

Publication details, including instructions for authors and subscription information:

http:// www.tandfonline.com/loi/ ceth20

\section{Socioeconomic disparities in physical health among Aboriginal and Torres Strait Islander children in Western Australia}

Carrington C.J. Shepherd ${ }^{\mathrm{a} b}$, J ianghong $\mathrm{Li}^{\mathrm{a} b} \&$ Stephen R. Zubrick $^{b}$

a Centre for Population Health Research, Curtin Health Innovation Research Institute, Curtin University, Perth, Australia

b Telethon Institute for Child Health Research, Centre for Child Health Research, University of Western Australia, Perth, Australia

Version of record first published: 31 J an 2012

To cite this article: Carrington C.J. Shepherd, Jianghong Li \& Stephen R. Zubrick (2012): Socioeconomic disparities in physical health among Aboriginal and Torres Strait Islander children in Western Australia, Ethnicity \& Health, DOI: 10.1080/ 13557858.2012.654768

To link to this article: http:// dx.doi.org/ 10.1080/ 13557858.2012.654768

\section{iFirst}

\section{PLEASE SCROLL DOWN FOR ARTICLE}

Full terms and conditions of use: http://www.tandfonline.com/page/terms-andconditions

This article may be used for research, teaching, and private study purposes. Any substantial or systematic reproduction, redistribution, reselling, loan, sub-licensing, systematic supply, or distribution in any form to anyone is expressly forbidden.

The publisher does not give any warranty express or implied or make any representation that the contents will be complete or accurate or up to date. The accuracy of any instructions, formulae, and drug doses should be independently verified with primary sources. The publisher shall not be liable for any loss, actions, claims, proceedings, 


\title{
Socioeconomic disparities in physical health among Aboriginal and Torres Strait Islander children in Western Australia
}

\author{
Carrington C.J. Shepherd ${ }^{\mathrm{a}, \mathrm{b} *}$, Jianghong $\mathrm{Li}^{\mathrm{a}}{ }^{\mathrm{a} b}$ and Stephen R. Zubrick ${ }^{\mathrm{b}}$ \\ ${ }^{a}$ Centre for Population Health Research, Curtin Health Innovation Research Institute, Curtin \\ University, Perth, Australia; ${ }^{b}$ Telethon Institute for Child Health Research, Centre for Child \\ Health Research, University of Western Australia, Perth, Australia
}

(Received 10 January 2011; final version received 28 November 2011)

\begin{abstract}
Objective. Few empirical studies have specifically examined the relationship between socio-economic status (SES) and health in Indigenous populations of Australia. We sought to provide insights into the nature of this relationship by examining socio-economic disparities in physical health outcomes among Aboriginal and Torres Strait Islander children in Western Australia.

Design. We used a diverse set of health and SES indicators from a representative survey conducted in 2000-2002 on the health and development of 5289 Indigenous children aged 0-17 years in Western Australia. Analysis was conducted using multivariate logistic regression within a multilevel framework.

Results. After controlling for age and sex, we found statistically significant socioeconomic disparities in health in almost half of the associations that were investigated, although the direction, shape and magnitude of associations differed. For ear infections, recurring chest infections and sensory function problems, the patterns were generally consistent with a positive socio-economic gradient - where better health was associated with higher SES. The reverse pattern was found for asthma, accidents and injuries, and oral health problems, although this was primarily observed for area-level SES indicators.

Conclusion. Conventional notions of social position and class have some influence on the physical health of Indigenous children, although the diversity of results implies that there are other ways of conceptualising and measuring SES that are important for Indigenous populations. We need to consider factors that relate specifically to Indigenous circumstances and culture in the past and present day, and give more thought to how we measure social position in the Indigenous community, to gain a better understanding of the pathways from SES to Indigenous child health.
\end{abstract}

Keywords: socio-economic; Aboriginal; physical health; Indigenous; inequality; Australia

\section{Introduction}

Socioeconomic factors have consistently been shown to influence population health (Adler 1999, Marmot and Wilkinson 2006). These factors reflect the way in which society is ordered according to wealth, prestige, power, social standing or one's control over economic resources (Mueller and Parcel 1981). The pattern of association between socio-economic status (SES) and health has almost always

*Corresponding author. Email: carringtons@ichr.uwa.edu.au 
depicted better health for those who are better off, regardless of how SES is defined or measured - that is, the health of population groups normally follows a gradient pattern (Keating and Hertzman 1999), at all stages of the life course (Case et al. 2002, Chen et al. 2005, Adler and Rehkopf 2008). Despite the ubiquity of this observation in the empirical literature, there is uncertainty as to whether it applies to Aboriginal and Torres Strait Islander (herein referred to as Aboriginal) populations in Australia (Morrissey 2003, Anderson 2007).

There are important implications of improving our understanding of socioeconomic disparities in health within Aboriginal populations. The magnitude and shape of disparities can provide insights into the relative importance of social conditions to health outcomes and may facilitate a better grasp of the complex underlying mechanisms that determine Indigenous health (Adler 1993, Macintyre 1994). Moreover, there are critical policy implications of improving our knowledge in this area. If the relationships between SES and health are relatively weak in Indigenous populations then investments aimed at stimulating employment, income and education, for example, are unlikely to improve the health outcomes of Indigenous populations or significantly reduce health disparities between Indigenous and other populations. This implies that policy responses that are suitable for the general population would need to be modified in order to benefit the health of Indigenous peoples.

The quality and quantity of data that describe the circumstances of Australian Aboriginal peoples has improved markedly in recent decades (Australian Bureau of Statistics 2007). These data reveal striking disparities between Aboriginal and nonAboriginal populations in most domains of health and constructs of SES (Steering Committee for the Review of Government Service Provision (SCRGSP) 2009), which reflect a post-colonial history of marginalisation and exclusion from mainstream society, dispossession of traditional lands, forced separation from family and kinship networks, and racism (Saggers and Gray 1991, Hunter 1993, Human Rights and Equal Opportunity Commission 1997, Anderson et al. 2006, Paradies et al. 2008).

The comparatively poorer health status of Australian Aboriginals is evident across the life course, including the earliest stages of life. Aboriginal children are more likely than non-Aboriginal children to be born at sub-optimal weight, die in infancy, suffer from a range of long-term health conditions, and be hospitalised (Blair 1996, Alessandri et al. 2001, Freemantle et al. 2006, Leeds et al. 2007, Australian Bureau of Statistics and Australian Institute of Health and Welfare 2008). Some conditions affecting Aboriginal children are scarcely encountered outside of Third World countries (such as rheumatic fever) and, too often, child illnesses, hospitalisations, disabilities and deaths are caused by potentially preventable events (such as injury, poisoning, abuse and neglect) (Australian Bureau of Statistics and Australian Institute of Health and Welfare 2008). While Indigenous/non-Indigenous health disparities are now well documented, less is known about the health disparities that exist within Indigenous populations in Australia.

The empirical evidence on socio-economic disparities in health in Indigenous Australia covers only a narrow range of health and SES indicators, with little consistency in scope or analytical approach. There are examples of socio-economic gradients in mortality, cardiovascular disease, renal disease, diabetes, disability, oral health, infections and self-rated overall health (Cunningham et al. 1997, Australian Bureau of Statistics 2004, Cass et al. 2004, Glover et al. 2004, Jamieson et al. 2006, 
Cunningham et al. 2008, Oddy et al. 2008, Cunningham 2010a, 2010b), although the slope and direction of these gradients typically varies across studies. Mental health, asthma and long-term health conditions appear to be equally prevalent across SES categories (Hunter, 1999, 2000, Zubrick et al. 2005, Cunningham 2010c), and a single study on birthweight was inconclusive as to whether outcomes varied significantly by an area-based measure of relative disadvantage (Titmuss et al. 2008). In some cases, the SES-health pattern has been shown to vary depending on the SES construct used. For example, Cunningham et al. highlighted that better self-rated health was associated with better education and labour force outcomes and home ownership, but not with household income, in a 1994 survey of Aboriginal adults (Cunningham et al. 1997).

This study aims to provide insights into the nature of the relationship between SES and health among Aboriginal peoples, with a focus on the socio-economic disparities in physical health outcomes of Aboriginal children in Western Australia. We use a diverse set of health outcome indicators and investigate the pattern of their associations with conventional and alternative measures of SES, including the characteristics of individuals, families, households and communities.

\section{Methods}

Data are from the 2000-2002 Western Australian Aboriginal Child Health Survey, a population representative study of the health, development and education of 5289 (or one in six) Aboriginal children aged 0-17 years in the state of Western Australia, and their families and communities. The survey used an area-based clustered multistage sample design. Dwellings in selected census collection districts (CDs) were approached, with in-scope families defined by whether there was an Aboriginal or Torres Strait Islander child aged 0-17 years living in the dwelling. All Aboriginal children aged $0-17$ years in in-scope families were selected to participate. Of eligible families, $84 \%$ consented to participate in the survey and useable information was obtained on $96 \%$ of participating children, predominantly from household interviews. In addition to data on the health of children, interviews were conducted among primary carers and, where possible, secondary carers of children to gather information on the demographic and social circumstances of families, households and the communities in which they lived. Primary and secondary carers were the people who spent the most time with survey children and knew them best. The primary carer was usually the mother of the child $(80 \%)$. In the majority of cases, the secondary carer was the father of the child $(77 \%)$ or another related person $(19 \%)$. Most primary $(83 \%)$ and secondary $(79 \%)$ carers identified themselves as Aboriginal. All aspects of the survey were conducted under the direction of a steering committee of senior Aboriginal people from a cross-section of settings and organisations. The full details of the design and conduct of the study have been described elsewhere (Silburn et al. 2006).

\section{Health outcomes}

Six physical health indicators were analysed, including chronic conditions (asthma, sensory function problems, recurring chest infections and oral health problems) and acute conditions (ear infections and accidents and injuries). These conditions 
represent some of the most prevalent long-term conditions (e.g., asthma) and those with significant contributions to hospitalisation (e.g., ear infections), mortality (e.g., injury) and the overall disease burden in childhood and young adulthood (Australian Bureau of Statistics and Australian Institute of Health and Welfare 2008, Australian Institute of Health and Welfare 2009, Australian Institute of Health and Welfare 2011). Information on all health outcomes was gathered from primary carers of participating children. Questions on sensory function and oral health problems and accidents and injuries were restricted to 4-17-year-olds. To determine asthma prevalence, carers were simply asked whether the child had 'ever had asthma'. Four questions were used to assess whether a child had a sensory function problem: Does the child have normal hearing in both ears? Does the child have normal vision in both eyes? Do other people need help to understand what the child is saying? Does the child have difficulty saying certain sounds? A limitation in one or more of these areas was considered a sensory function problem for the purposes of this study. Children who had ever had holes in their teeth, teeth removed, fillings, or sore/bleeding gums were deemed to have had an oral health problem. A child was classified as having an ear infection if they experienced recurring ear infections or a single episode of discharging ear(s) (runny, tropical or glue ear). Accidents and injuries were assessed by asking whether the child had ever: broken a bone(s); been knocked out; or had a stay in hospital because of an accidental burn or poisoning.

\section{SES measures}

Socioeconomic status was measured using eight separate variables, including characteristics of parents/carers (educational attainment of both primary and secondary carers and highest occupational class of carers), families/households (family financial strain, housing tenure, housing quality) and neighbourhoods/ communities (two composite indexes of socio-economic disadvantage). This array of measures was chosen for four main reasons. First, reliance on a single measure is unlikely to capture how socio-economic position shapes health disparities in any population. This is particularly true among Indigenous populations because they are more likely to be distributed at the lower levels of any SES construct. Second, it is necessary to measure different dimensions of SES at multiple levels in order to capture the complex set of factors that contribute to socio-economic disadvantage among Aboriginal populations. Third, use of multiple SES measures enables a comparison of compositional and contextual effects on health disparities. Fourth, it is important to test the saliency of conventional versus alternative SES indicators in shaping health disparities, particularly as there are doubts about the relevance of conventional SES measures for Indigenous and other disadvantaged populations (Altman 2000, Shavers 2007, Taylor 2008). We have included conventional indicators of social class (education and occupation) and used a subjective rating of financial strain as a proxy measure of material well-being. Financial strain is used in preference to a conventional measure of household income, for two main reasons: first, income data was not collected from all household members who contributed to its financial base; and second, income does not capture the nature of sharing of economic resources that can occur between extended members of Indigenous families (Hunter et al. 2003). Housing characteristics are afforded prominence in these analyses, given the importance of housing to Indigenous health (Bailie and 
Runcie 2001). Housing tenure and quality are proxy indicators of income and wealth (Shaw 2004) and have been included to complement the measure of financial strain (income) in describing the material wealth of Indigenous families and households.

Information about the characteristics of primary carers, families and households was provided by the primary carers of participating children. Secondary carers provided separate responses on their educational attainment and occupational class. Housing quality was measured using a set of indicators based on a nationally agreed framework for the design, construction and maintenance of Indigenous housing (Silburn et al. 2006). This includes whether the house had facilities for washing people and clothes, removing waste safely, storing and cooking food and controlling the temperature. Households were classified into one of four categories: having none, one, two or three or more indicators of poor housing quality.

The Australian Bureau of Statistics' Socioeconomic Index for Areas (SEIFA) product and Biddle's Index of Relative Indigenous Socioeconomic Outcomes (IRISEO) were used to measure area-level socio-economic disadvantage (Australian Bureau of Statistics 1998, Biddle 2009). The SEIFA index ranks the relative level of disadvantage of areas using the attributes of all persons (Indigenous and nonIndigenous) in each census CD. The SEIFA index used in this study includes measures of income, educational attainment, employment status and occupational skill but excludes the proportion of Indigenous people in the CD (Silburn et al. 2006). Quintiles were determined based on the distribution of values for all Australian CDs. Biddle's IRISEO is a rank order variable that measures the socioeconomic outcomes of all 531 Indigenous Areas in Australia in 2001, based on the employment, income, education and housing characteristics of Indigenous persons only (Biddle 2009). Quintiles were determined based on the distribution of IRISEO values for all Australian Indigenous Areas.

\section{Geographic isolation}

Geographic isolation is defined using the Level of Relative Isolation (LORI) classification, which is based on the ARIA ++ index (a widely used classification of remoteness in Australia). The five categories of isolation reflect differences in access to services, cultures and health outcomes for Aboriginal children in Western Australia, and range from none (Perth metropolitan area), to low, moderate, high and extreme (Zubrick et al. 2004).

\section{Non-response and imputation}

Analysis of non-response characteristics showed that the survey sample was broadly representative of the population of Aboriginal children living in Western Australia, although comparisons with population benchmarks showed that age, SES, household size and region were significantly associated with non-response. Post-stratification weighting was employed to adjust for differential non-response and produce unbiased estimates. There was only a small amount of item-level non-response. While an imputation procedure was employed to assign values to non-responding items, the percentage of imputed values was less than $1 \%$ for each variable and, based on this, imputation had no effect on the results of this study. Information was unable to be obtained on the characteristics of $15 \%$ of secondary carers, and we have treated all 
variables from these records as missing in the following analysis. More details about non-response characteristics, weighting and imputation are available elsewhere (Zubrick et al. 2004).

\begin{abstract}
Analysis
Analysis was conducted using logistic regression techniques within a multilevel framework. Models were fitted with the method described by Pfeffermann et al. which takes into account the survey weights and the hierarchical structure of the data, i.e., selection of children within families and communities (Pfeffermann et al. 1998). All models report odds ratios, adjusted for age and sex, with $95 \%$ confidence intervals. Standard errors for survey estimates of totals were produced using the Ultimate Cluster Variance estimation technique (Wolter 1985). Standard errors for estimates of odds ratios and proportions were calculated using a modified form of the Jack knife variance estimation technique (Jones 1974). Standard chi-square tests and chi-square tests for trend adjusted for the complex sample design were used to assess the difference between categorical SES indicators and dichotomised health outcome variables. Spline curves were used to further describe the shape of the association between SEIFA and health, and to assess the impact of geographic isolation (LORI) on the SES-health relationship. We used the Generalized Additive Models framework to account for the possible non-linear nature of these relationships and fit a non-parametric Spline curve (Hastie and Tibshirani 1990). SAS version 9.2 was used for all analyses (SAS Institute Inc., Cary, NC, USA, 2000-2008).
\end{abstract}

\title{
Ethical approvals
}

This study was conducted under ethical approvals from Curtin University's Human Research Ethics Committee and the Western Australian Aboriginal Health Information and Ethics Committee, and was endorsed by the Aboriginal Collaborative Council Advising Research and Evaluation at the Telethon Institute for Child Health Research.

\section{Results \\ Population characteristics}

The six indicators of physical health ranged in prevalence, from $12 \%$ (for recurring chest infections) to $47 \%$ (for oral health problems) (Table 1). Aboriginal children were largely distributed in the more disadvantaged categories of most measures of SES, with few represented in the top category: only 5\% of Aboriginal children had a primary carer with a post-secondary education, $5 \%$ lived in a family who could 'save a lot', 6\% lived in houses who were owned by its occupants, and 5\% lived in areas coded to the top two SEIFA quintiles. When area-level relative disadvantage was constructed using the characteristics of Aboriginal people only (IRISEO), $17 \%$ of our study population was in the top two quintiles (Table 1). This signals that, on average, Aboriginal children in Western Australia live in areas with less favourable socio-economic characteristics than other Aboriginal people across Australia. 
Table 1. Health, SES and demographic characteristics of Aboriginal children aged 0-17 years in Western Australia, 2000-2002. ${ }^{\mathrm{a}}$

\begin{tabular}{|c|c|c|}
\hline & Number & Percentage $(95 \% \mathrm{CI})$ \\
\hline \multicolumn{3}{|l|}{ Health characteristics } \\
\hline Asthma & 6910 & $23.2(21.6-24.9)$ \\
\hline Ear infections & 8160 & $27.4(25.8-29.0)$ \\
\hline Recurring chest infections & 3660 & $12.3(11.1-13.5)$ \\
\hline Sensory function problem ${ }^{\mathrm{b}}$ & 5560 & $24.3(22.4-26.3)$ \\
\hline Injury or accident ${ }^{b}$ & 5220 & $22.8(21.2-24.4)$ \\
\hline Oral health problem ${ }^{\mathrm{b}}$ & 10,700 & $46.6(44.3-48.9)$ \\
\hline \multicolumn{3}{|l|}{ SES characteristics } \\
\hline \multicolumn{3}{|l|}{ Education: primary carer } \\
\hline Did not attend & 740 & $2.5(1.8-3.4)$ \\
\hline Year 9 or less & 6630 & $22.2(20.3-24.3)$ \\
\hline Year 10 & 12,800 & $42.9(40.6-45.3)$ \\
\hline Years $11-12$ & 7240 & $24.3(22.3-26.4)$ \\
\hline 13 or more years & 1600 & $5.4(4.0-6.9)$ \\
\hline \multicolumn{3}{|l|}{ Education: secondary carer } \\
\hline Did not attend & 700 & $2.4(1.6-3.4)$ \\
\hline Year 9 or less & 4880 & $16.4(14.6-18.2)$ \\
\hline Year 10 & 5910 & $19.8(17.8-22.1)$ \\
\hline Years $11-12$ & 3050 & $10.2(8.8-11.8)$ \\
\hline 13 or more years & 710 & $2.4(1.6-3.3)$ \\
\hline No secondary carer & 11,900 & $39.9(37.5-42.4)$ \\
\hline \multicolumn{3}{|l|}{ Occupation $^{\mathrm{c}}$} \\
\hline Managers and professionals & 3490 & $11.7(10.1-13.4)$ \\
\hline Tradespersons, clerical workers and labourers & 10,800 & $36.3(33.9-38.8)$ \\
\hline Not employed & 14,800 & $49.6(47.0-52.2)$ \\
\hline \multicolumn{3}{|l|}{ Family financial strain } \\
\hline Spending more than we get & 2630 & $8.8(7.5-10.3)$ \\
\hline Just enough to get by & 13,300 & $44.5(42.1-46.9)$ \\
\hline Some left over but spend it & 4010 & $13.5(11.7-15.3)$ \\
\hline Can save a bit & 7680 & $25.8(23.7-27.9)$ \\
\hline Can save a lot & 1420 & $4.8(3.7-6.1)$ \\
\hline \multicolumn{3}{|l|}{ Housing tenure } \\
\hline Owned & 1910 & $6.4(4.9-8.1)$ \\
\hline Being paid off & 4120 & $13.8(12.1-15.7)$ \\
\hline Renting & 21,800 & $73.0(70.5-75.4)$ \\
\hline Other & 1230 & $4.1(3.0-5.5)$ \\
\hline \multicolumn{3}{|l|}{ Number of indicators of poor housing quality } \\
\hline None & 8930 & $29.9(27.5-32.4)$ \\
\hline One & 7980 & $26.8(24.7-28.9)$ \\
\hline Two & 6480 & $21.9(19.8-24.2)$ \\
\hline Three or more & 6340 & $21.4(19.2-23.7)$ \\
\hline \multicolumn{3}{|l|}{ SEIFA $^{\mathrm{d}}$ (quintiles) } \\
\hline Bottom quintile (less advantaged) & 17,500 & $58.6(54.4-62.7)$ \\
\hline Second & 7310 & $24.5(21.1-28.0)$ \\
\hline
\end{tabular}


Table 1 (Continued)

\begin{tabular}{lrc}
\hline & Number & Percentage $(95 \%$ CI) \\
\hline Third & 3600 & $12.1(9.3-15.2)$ \\
Fourth & 1270 & $4.3(2.4-7.0)$ \\
Top quintile (more advantaged) & 170 & $0.6(0.1-1.6)$ \\
IRISEO $^{\text {e }}$ (quintiles) & & \\
Bottom quintile (less advantaged) $_{\text {Second }}$ & 6350 & $21.3(17.8-25.0)$ \\
Third & 8760 & $29.4(26.1-33.0)$ \\
Fourth & 9490 & $31.8(28.8-35.0)$ \\
Top quintile (more advantaged) & 4830 & $16.2(13.7-18.9)$ \\
Demographics & 300 & $1.0(0.4-2.4)$ \\
Age (years) & & \\
$0-3$ & & \\
$4-11$ & 6910 & $23.2(21.7-24.7)$ \\
12-17 & 13,800 & $46.5(44.8-48.2)$ \\
Sex & 9100 & $30.3(28.5-32.1)$ \\
Male & & \\
Female & 15,370 & $51.6(49.9-53.1)$ \\
Level of relative isolation & 14,430 & $48.4(46.9-50.1)$ \\
None & & \\
Low & 10,200 & $34.1(31.5-36.8)$ \\
Moderate & 7270 & $24.4(21.8-27.0)$ \\
High & 6390 & $21.4(18.1-25.1)$ \\
Extreme & 3170 & $10.6(7.9-14.0)$ \\
& 2830 & $9.5(6.8-12.7)$ \\
\hline
\end{tabular}

${ }^{a}$ Numbers are weighted estimates of the population of Aboriginal children in each category, and have been rounded. Proportions for sensory function problems, injuries/accidents and oral health problems are based on all Aboriginal children aged 4-17 years $(n=22,900)$; all other proportions are based on all Aboriginal children aged $0-17$ years $(n=29,800)$. The frequencies of missing responses have not been reported.

${ }^{\mathrm{b}}$ For 4-17-year-olds only.

${ }^{\mathrm{c}}$ Highest occupational class of primary and secondary carers. Occupation categories have been dichotomised based on skill levels defined in the Australian Standard Classification of Occupations, second edition. 'Managers and professionals' include occupational skill levels 1 and 2. 'Tradespersons, clerical workers and labourers' include occupational skill levels 3-5.

${ }^{\mathrm{d}}$ Customised version of the index of relative socio-economic disadvantage that forms part of the Australian Bureau of Statistics' Socioeconomic Index for Areas (SEIFA) product. Quintiles were determined based on the distribution of values for all Australian CDs.

'Biddle's Index of Relative Indigenous Socioeconomic Outcomes. The index was derived using the characteristics of Indigenous persons only and quintiles were determined based on the distribution of values for all Australian Indigenous Areas.

\section{SES-health disparities}

Tables 2 and 3 show the odds ratios from logistic regression analyses, and highlight that the direction and magnitude of the association between SES and health varied greatly by both SES indicator and health outcome. Overall, of the 48 associations examined, 17 were statistically significant on the basis of a chi-square test for trend, and another 7 had at least one significant difference (at a 95\% level of confidence) in health status between categories of SES. For ear infections, recurring chest infections and sensory function problems, the patterns were generally consistent with a positive 
Table 2. Socioeconomic disparities in selected physical health outcomes among Indigenous children aged 0-17 years, Western Australia, 2000-2002. ${ }^{\text {a }}$

\begin{tabular}{|c|c|c|c|c|c|c|c|c|c|}
\hline \multirow[b]{2}{*}{ Socioeconomic measure } & \multicolumn{3}{|c|}{ Asthma } & \multicolumn{3}{|c|}{ Ear infections } & \multicolumn{3}{|c|}{ Recurring chest infections } \\
\hline & OR & $95 \% \mathrm{CI}$ & $p$ Value $^{\mathrm{b}}$ & OR & $95 \% \mathrm{CI}$ & $p$ Value $^{\mathrm{b}}$ & OR & $95 \% \mathrm{CI}$ & $p$ Value $^{\mathrm{b}}$ \\
\hline \multicolumn{10}{|l|}{ Carer characteristics } \\
\hline \multicolumn{10}{|l|}{ Education: primary carer } \\
\hline Did not attend & 0.60 & $0.33-1.36$ & 0.089 & 1.90 & $1.21-2.98$ & 0.007 & 2.35 & $0.98-5.67$ & 0.362 \\
\hline Year 9 or less & 0.75 & $0.64-1.04$ & & 1.34 & $1.05-1.71$ & & 0.94 & $0.71-1.25$ & \\
\hline Year 10 & 1.00 & & & 1.00 & .. & & 1.00 & & \\
\hline Years 11-12 & 1.08 & $0.84-1.36$ & & 1.26 & $0.98-1.63$ & & 1.05 & $0.80-1.38$ & \\
\hline 13 or more years & 1.33 & $0.89-1.86$ & & 1.63 & $1.09-2.45$ & & 1.19 & $0.76-1.85$ & \\
\hline \multicolumn{10}{|l|}{ Education: secondary carer } \\
\hline Did not attend & 0.89 & $0.48-1.57$ & 0.343 & 2.10 & $1.04-4.24$ & 0.002 & 0.97 & $0.45-2.08$ & 0.305 \\
\hline Year 9 or less & 0.90 & $0.67-1.19$ & & 1.36 & $1.00-1.85$ & & 1.03 & $0.70-1.51$ & \\
\hline Year 10 & 1.00 & & & 1.00 & .. & & 1.00 & .. & \\
\hline Years 11-12 & 1.31 & $0.88-1.69$ & & 0.98 & $0.68-1.42$ & & 0.78 & $0.50-1.21$ & \\
\hline 13 or more years & 0.85 & $0.44-1.88$ & & 0.42 & $0.20-0.88$ & & 0.76 & $0.39-1.45$ & \\
\hline No secondary carer & 1.22 & $0.90-1.45$ & & 1.42 & $1.09-1.85$ & & 1.13 & $0.81-1.57$ & \\
\hline \multicolumn{10}{|l|}{ Occupation $^{\mathrm{c}}$} \\
\hline Managers/professionals & 1.08 & $0.70-1.67$ & 0.736 & 1.28 & $0.93-1.77$ & 0.125 & 1.07 & $0.73-1.58$ & 0.718 \\
\hline Tradespersons, clerical workers and labourers & 1.00 & .. & .. & 1.00 & .. & .. & 1.00 & .. & .. \\
\hline Not employed & 1.01 & $0.79-1.30$ & 0.907 & 1.04 & $0.84-1.29$ & 0.702 & 1.35 & $1.05-1.75$ & 0.021 \\
\hline \multicolumn{10}{|l|}{ Family/household characteristics } \\
\hline \multicolumn{10}{|l|}{ Family financial strain } \\
\hline Spending more than we get & 0.95 & $0.49-1.84$ & 0.857 & 1.11 & $0.56-2.19$ & 0.366 & 2.65 & $1.33-5.27$ & 0.015 \\
\hline Just enough to get by & 0.88 & $0.47-1.62$ & & 1.05 & $0.58-1.90$ & & 1.72 & $0.91-3.24$ & \\
\hline Some left over but spend it & 0.78 & $0.41-1.50$ & & 1.12 & $0.60-2.09$ & & 1.37 & $0.69-2.69$ & \\
\hline Can save a bit & 0.96 & $0.53-1.76$ & & 0.86 & $0.47-1.60$ & & 1.52 & $0.81-2.84$ & \\
\hline Can save a lot & 1.00 &.. & & 1.00 & .. & & 1.00 & .. & \\
\hline \multicolumn{10}{|l|}{ Housing tenure } \\
\hline Owned & 1.00 & .. & .. & 1.00 & .. & .. & 1.00 & .. & .. \\
\hline Being paid off & 1.97 & $1.00-3.88$ & 0.049 & 0.91 & $0.54-1.55$ & 0.729 & 0.57 & $0.34-0.97$ & 0.037 \\
\hline Renting & 1.90 & $1.02-3.53$ & 0.042 & 1.14 & $0.71-1.82$ & 0.594 & 0.83 & $0.53-1.30$ & 0.423 \\
\hline Other & 0.66 & $0.23-1.91$ & 0.440 & 1.42 & $0.71-2.83$ & 0.324 & 0.53 & $0.21-1.33$ & 0.176 \\
\hline
\end{tabular}


Table 2 (Continued)

\begin{tabular}{|c|c|c|c|c|c|c|c|c|c|}
\hline \multirow[b]{2}{*}{ Socioeconomic measure } & \multicolumn{3}{|c|}{ Asthma } & \multicolumn{3}{|c|}{ Ear infections } & \multicolumn{3}{|c|}{ Recurring chest infections } \\
\hline & OR & $95 \% \mathrm{CI}$ & $p$ Value $^{\mathrm{b}}$ & OR & $95 \% \mathrm{CI}$ & $p$ Value $^{\mathrm{b}}$ & OR & $95 \% \mathrm{CI}$ & $p$ Value $^{\mathrm{b}}$ \\
\hline \multicolumn{10}{|c|}{ Number of indicators of poor housing quality } \\
\hline None & 1.00 & .. & 0.018 & 1.00 & & $<0.001$ & 1.00 & .. & 0.237 \\
\hline One & 0.99 & $0.76-1.30$ & & 0.97 & $0.73-1.29$ & & 1.20 & $0.89-1.62$ & \\
\hline Two & 0.94 & $0.68-1.29$ & & 1.28 & $0.96-1.69$ & & 1.31 & $0.97-1.77$ & \\
\hline Three or more & 0.60 & $0.43-0.85$ & & 1.55 & $1.21-2.00$ & & 1.32 & $0.97-1.81$ & \\
\hline \multicolumn{10}{|c|}{$\begin{array}{l}\text { Neighbourhood characteristics } \\
\text { SEIFA quintiles }{ }^{\mathrm{d}}\end{array}$} \\
\hline Bottom quintile & 1.00 & .. & 0.001 & 1.00 & & 0.790 & 1.00 & .. & 0.237 \\
\hline Second & 1.48 & $1.10-2.00$ & & 1.18 & $0.90-1.55$ & & 0.90 & $0.69-1.17$ & \\
\hline Third & 1.80 & $1.29-2.51$ & & 1.10 & $0.80-1.50$ & & 0.85 & $0.58-1.22$ & \\
\hline Fourth & 1.41 & $0.83-2.37$ & & 1.14 & $0.69-1.88$ & & 0.84 & $0.53-1.34$ & \\
\hline Top quintile & 3.48 & $1.34-9.04$ & & 1.06 & $0.41-2.74$ & & 0.38 & $0.16-0.93$ & \\
\hline \multicolumn{10}{|l|}{ IRISEO quintiles $^{\mathrm{e}}$} \\
\hline Bottom quintile & 1.00 &.. & $<0.001$ & 1.00 & .. & 0.001 & 1.00 & .. & 0.407 \\
\hline Second & 3.37 & $2.07-5.49$ & & 0.68 & $0.50-0.90$ & & 1.06 & $0.78-1.46$ & \\
\hline Third & 3.91 & $2.42-6.31$ & & 0.54 & $0.40-0.73$ & & 0.92 & $0.66-1.28$ & \\
\hline Fourth & 4.66 & $2.80-7.74$ & & 0.56 & $0.38-0.84$ & & 1.24 & $0.86-1.79$ & \\
\hline Top quintile & 9.24 & $3.10-27.20$ & & 0.47 & $0.22-1.04$ & & 0.69 & $0.27-1.81$ & \\
\hline
\end{tabular}

${ }^{a}$ Results are derived from multivariate logistic regression models using a multi-level framework. All models are adjusted for age and sex. Each SES-health variable pair represents a separate model.

${ }^{\mathrm{b}}$ Calculated using chi-square tests adjusted for the complex sample design. Chi-square tests for trend were used for ordinal SES variables; standard chi-square tests were used for nominal SES variables.

${ }^{c}$ Highest occupational class of primary and secondary carers. Occupation categories have been dichotomised based on skill levels defined in the Australian Standard Classification of Occupations, second edition. 'Managers and professionals' include occupational skill levels 1 and 2. 'Tradespersons, clerical workers and labourers' include occupational skill levels $3-5$.

${ }^{\mathrm{d}}$ Customised version of the index of relative socio-economic disadvantage that forms part of the Australian Bureau of Statistics' Socioeconomic Index for Areas (SEIFA) product. Quintiles were determined based on the distribution of values for all Australian CDs.

${ }^{\mathrm{e}}$ Biddle's Index of Relative Indigenous Socioeconomic Outcomes. The index was derived using the characteristics of Indigenous persons only and quintiles were determined based on the distribution of values for all Australian Indigenous Areas. 
socio-economic gradient - where better health was associated with higher SES. Conversely, asthma, accidents and injuries, and oral health problems tended to exhibit a reverse gradient - where better health was associated with lower SES, although this was primarily observed for area-level SES indicators.

The largest differences in health outcomes were observed for area-level SES indicators, with other SES measures generally showing a weak to moderate association with the health outcomes. For example, Aboriginal children aged 0-17 years in the top quintile of the IRISEO were 9.2 times more likely ( $95 \%$ CI: $3.1-27.2$ ) to have ever had asthma than those in the bottom quintile; whereas there was generally less than a two-fold disparity in the health outcomes within parental, family and household-level SES indicators.

Most health outcomes had a curvilinear pattern of association with SEIFA (Figure 1), although not all of these were statistically significant. There was evidence of a reverse threshold effect for oral health problems and asthma, whereby those in the lowest quintile of SEIFA generally had better health outcomes than all others. The relationship with the IRISEO was characterised by a reverse gradient for four of the six health variables. These gradients tended to be linear, reflecting monotonic changes in health status along the continuum of this index.

The pattern of health disparities by family financial strain was generally consistent with a positive socio-economic gradient (Figure 2). This pattern was strongest for recurring chest infections: children in families who described their financial situation as 'spending more than we get' were 2.6 times more likely $(95 \% \mathrm{CI}: 1.3-5.3)$ to experience recurring chest infections than children in families who could 'save a lot' (Figure 2).

There was no clear pattern in health disparities for housing characteristics, such as tenure and housing quality. This reflects a lack of consistency in the direction of the associations and generally modest effect sizes.

The strength and shape of the associations with primary carer education varied: there was a U-shaped relationship with both ear infections and oral health - with the worst health outcomes found when primary carers had not attended school or had 13 or more years of education; and a pronounced positive gradient with sensory function problems. Few of the results by secondary carer educational attainment reached statistical significance. Most of the odds ratios for carer occupation were close to the null value, with the exceptions reflecting differences in employment status rather than occupational skill. For example, children without an employed carer had a slightly elevated likelihood of experiencing recurring chest infections (OR: 1.4; 95\% CI: 1.1-1.8) and an accident/injury (OR: 1.3; 95\% CI: 1.0-1.5) than other children.

The pattern of disparities presented here does not differ appreciably when all SES variables are considered simultaneously in the models (data not shown). This is not surprising given only weak to moderation associations among these SES indicators, as shown in Table 4. Further, the majority of the SES-health associations are not significantly attenuated by the inclusion of geographic isolation in the models, with the exception of associations between IRISEO and asthma, ear infections and oral health problems (data not shown). In these instances, the effect sizes were diminished, although the association with oral health remained statistically significant (Figure 3 provides an example, using asthma). 
Table 3. Socioeconomic disparities in selected physical health outcomes among Indigenous children aged 4-17 years, Western Australia, 2000-2002 ${ }^{\mathrm{a}}$.

\begin{tabular}{|c|c|c|c|c|c|c|c|c|c|}
\hline \multirow[b]{2}{*}{ Socioeconomic measure } & \multicolumn{3}{|c|}{ Injury/accident } & \multicolumn{3}{|c|}{ Sensory function problem } & \multicolumn{3}{|c|}{ Oral health problem } \\
\hline & OR & $95 \% \mathrm{CI}$ & $p$ Value $^{\mathrm{b}}$ & OR & $95 \% \mathrm{CI}$ & $p$ Value $^{\mathrm{b}}$ & OR & $95 \% \mathrm{CI}$ & $p$ Value $^{\mathrm{b}}$ \\
\hline \multicolumn{10}{|l|}{ Carer characteristics } \\
\hline \multicolumn{10}{|l|}{ Education: primary carer } \\
\hline Did not attend & 0.83 & $0.39-1.77$ & 0.192 & 2.43 & $1.17-5.01$ & 0.037 & 1.75 & $0.93-3.28$ & 0.001 \\
\hline Year 9 or less & 1.05 & $0.84-1.31$ & & 1.05 & $0.80-1.39$ & & 0.71 & $0.54-0.92$ & \\
\hline Year 10 & 1.00 & .. & & 1.00 & .. & & 1.00 & .. & \\
\hline Years $11-12$ & 1.09 & $0.87-1.36$ & & 1.25 & $0.94-1.67$ & & 1.04 & $0.79-1.36$ & \\
\hline 13 or more years & 1.57 & $1.07-2.30$ & & 0.77 & $0.44-1.37$ & & 1.51 & $1.00-2.30$ & \\
\hline \multicolumn{10}{|l|}{ Education: secondary carer } \\
\hline Did not attend & 1.47 & $0.86-2.52$ & 0.175 & 1.20 & $0.47-3.03$ & 0.308 & 0.41 & $0.19-0.90$ & 0.066 \\
\hline Year 9 or less & 0.99 & $0.75-1.32$ & & 0.83 & $0.57-1.21$ & & 0.73 & $0.53-1.00$ & \\
\hline Year 10 & 1.00 & .. & & 1.00 & .. & & 1.00 & .. & \\
\hline Years 11-12 & 0.79 & $0.55-1.13$ & & 1.50 & $0.94-2.39$ & & 0.57 & $0.36-0.89$ & \\
\hline 13 or more years & 1.57 & $0.83-3.00$ & & 0.73 & $0.35-1.53$ & & 0.49 & $0.22-1.12$ & \\
\hline No secondary carer & 1.05 & $0.84-1.32$ & & 1.05 & $0.79-1.41$ & & 0.85 & $0.65-1.13$ & \\
\hline \multicolumn{10}{|l|}{ Occupation $^{\mathrm{c}}$} \\
\hline Managers/professionals & 1.26 & $0.92-1.73$ & 0.52 & 0.99 & $0.69-1.42$ & 0.948 & 0.93 & $0.66-1.30$ & 0.664 \\
\hline Tradespersons, clerical workers and labourers & 1.00 & .. & .. & .. & .. & .. &.. & .. & .. \\
\hline Not employed & 1.25 & $1.02-1.52$ & 0.028 & 0.95 & $0.76-1.19$ & 0.673 & 0.93 & $0.75-1.16$ & 0.523 \\
\hline \multicolumn{10}{|l|}{ Family/household characteristics } \\
\hline \multicolumn{10}{|l|}{ Family financial strain } \\
\hline Spending more than we get & 1.59 & $0.91-2.79$ & 0.211 & 1.31 & $0.67-2.56$ & 0.692 & 1.37 & $0.78-2.42$ & 0.412 \\
\hline Just enough to get by & 1.30 & $0.80-2.11$ & & 0.96 & $0.54-1.72$ & & 1.41 & $0.81-2.47$ & \\
\hline Some left over but spend it & 1.16 & $0.69-1.93$ & & 1.01 & $0.54-1.91$ & & 1.07 & $0.62-1.84$ & \\
\hline Can save a bit & 1.50 & $0.91-2.49$ & & 1.00 & $0.54-1.83$ & & 1.24 & $0.72-2.15$ & \\
\hline Can save a lot & 1.00 &.. & & 1.00 &.. & & 1.00 &.. & \\
\hline \multicolumn{10}{|l|}{ Housing tenure } \\
\hline Owned & 1.00 & .. & .. & 1.00 & .. & .. & 1.00 & .. & .. \\
\hline Being paid off & 0.99 & $0.61-1.60$ & 0.972 & 1.41 & $0.77-2.56$ & 0.264 & 0.91 & $0.57-1.46$ & 0.700 \\
\hline
\end{tabular}


Table 3 (Continued)

\begin{tabular}{|c|c|c|c|c|c|c|c|c|c|}
\hline \multirow[b]{2}{*}{ Socioeconomic measure } & \multicolumn{3}{|c|}{ Injury/accident } & \multicolumn{3}{|c|}{ Sensory function problem } & \multicolumn{3}{|c|}{ Oral health problem } \\
\hline & OR & $95 \% \mathrm{CI}$ & $p$ Value $^{\mathrm{b}}$ & OR & $95 \% \mathrm{CI}$ & $p$ Value $^{\mathrm{b}}$ & OR & $95 \% \mathrm{CI}$ & $p$ Value $^{\mathrm{b}}$ \\
\hline Renting & 0.92 & $0.61-1.40$ & 0.710 & 1.32 & $0.76-2.29$ & 0.333 & 0.66 & $0.44-0.99$ & 0.043 \\
\hline Other & 0.85 & $0.54-1.34$ & 0.483 & 0.91 & $0.38-2.19$ & 0.840 & 0.49 & $0.24-1.03$ & 0.060 \\
\hline \multicolumn{10}{|c|}{ Number of indicators of poor housing quality } \\
\hline None & 1.00 & . & 0.093 & 1.00 & & 0.982 & 1.00 & .. & $<0.001$ \\
\hline One & 1.19 & $0.90-1.56$ & & 1.05 & $0.78-1.42$ & & 0.89 & $0.68-1.16$ & \\
\hline Two & 1.23 & $0.92-1.64$ & & 1.03 & $0.72-1.46$ & & 0.72 & $0.54-0.96$ & \\
\hline Three or more & 0.90 & $0.69-1.16$ & & 1.06 & $0.77-1.46$ & & 0.52 & $0.38-0.70$ & \\
\hline \multicolumn{10}{|c|}{ Neighbourhood characteristics } \\
\hline \multicolumn{10}{|c|}{ SEIFA quintiles ${ }^{\mathrm{d}}$} \\
\hline Bottom quintile & 1.00 & & 0.225 & 1.00 & & 0.105 & 1.00 & .. & 0.001 \\
\hline Second & 1.16 & $0.93-1.45$ & & 1.07 & $0.81-1.41$ & & 1.10 & $0.83-1.47$ & \\
\hline Third & 1.28 & $0.97-1.67$ & & 1.37 & $0.86-2.19$ & & 1.43 & $1.05-1.96$ & \\
\hline Fourth & 1.08 & $0.69-1.68$ & & 0.48 & $0.25-0.91$ & & 0.55 & $0.37-0.82$ & \\
\hline Top quintile & 2.72 & $0.70-10.20$ & & 0.82 & $0.17-3.92$ & & 2.53 & $0.50-13.60$ & \\
\hline \multicolumn{10}{|l|}{ IRISEO quintiles ${ }^{\mathrm{e}}$} \\
\hline Bottom quintile & 1.00 &.. & $<0.001$ & 1.00 & .. & 0.041 & 1.00 & .. & $<0.0001$ \\
\hline Second & 1.50 & $1.14-1.99$ & & 1.81 & $1.17-2.79$ & & 2.72 & $1.85-4.01$ & \\
\hline Third & 1.79 & $1.36-2.36$ & & 1.61 & $1.08-2.39$ & & 2.98 & $2.03-4.36$ & \\
\hline Fourth & 1.70 & $1.26-2.31$ & & 1.61 & $1.05-2.49$ & & 2.98 & $1.93-4.60$ & \\
\hline Top quintile & 2.98 & $1.15-7.73$ & & 2.43 & $1.16-5.10$ & & 5.37 & $1.90-15.30$ & \\
\hline
\end{tabular}

${ }^{a}$ Results are derived from multivariate logistic regression models using a multi-level framework. All models are adjusted for age and sex. Each SES-health variable pair represents a separate model.

${ }^{\mathrm{b}}$ Calculated using chi-square tests adjusted for the complex sample design. Chi-square tests for trend were used for ordinal SES variables; standard chi-square tests were used for nominal SES variables.

${ }^{\mathrm{c}}$ Highest occupational class of primary and secondary carers. Occupation categories have been dichotomised based on skill levels defined in the Australian Standard Classification of Occupations, second edition. 'Managers and professionals' include occupational skill levels 1 and 2. 'Tradespersons, clerical workers and labourers' include occupational skill levels $3-5$.

${ }^{\mathrm{d} C u s t o m i s e d ~ v e r s i o n ~ o f ~ t h e ~ i n d e x ~ o f ~ r e l a t i v e ~ s o c i o-e c o n o m i c ~ d i s a d v a n t a g e ~ t h a t ~ f o r m s ~ p a r t ~ o f ~ t h e ~ A u s t r a l i a n ~ B u r e a u ~ o f ~ S t a t i s t i c s ' ~ S o c i o e c o n o m i c ~ I n d e x ~ f o r ~ A r e a s ~(S E I F A) ~}$ product. Quintiles were determined based on the distribution of values for all Australian CDs.

${ }^{\text {e}}$ Biddle's Index of Relative Indigenous Socioeconomic Outcomes. The index was derived using the characteristics of Indigenous persons only and quintiles were determined based on the distribution of values for all Australian Indigenous Areas. 


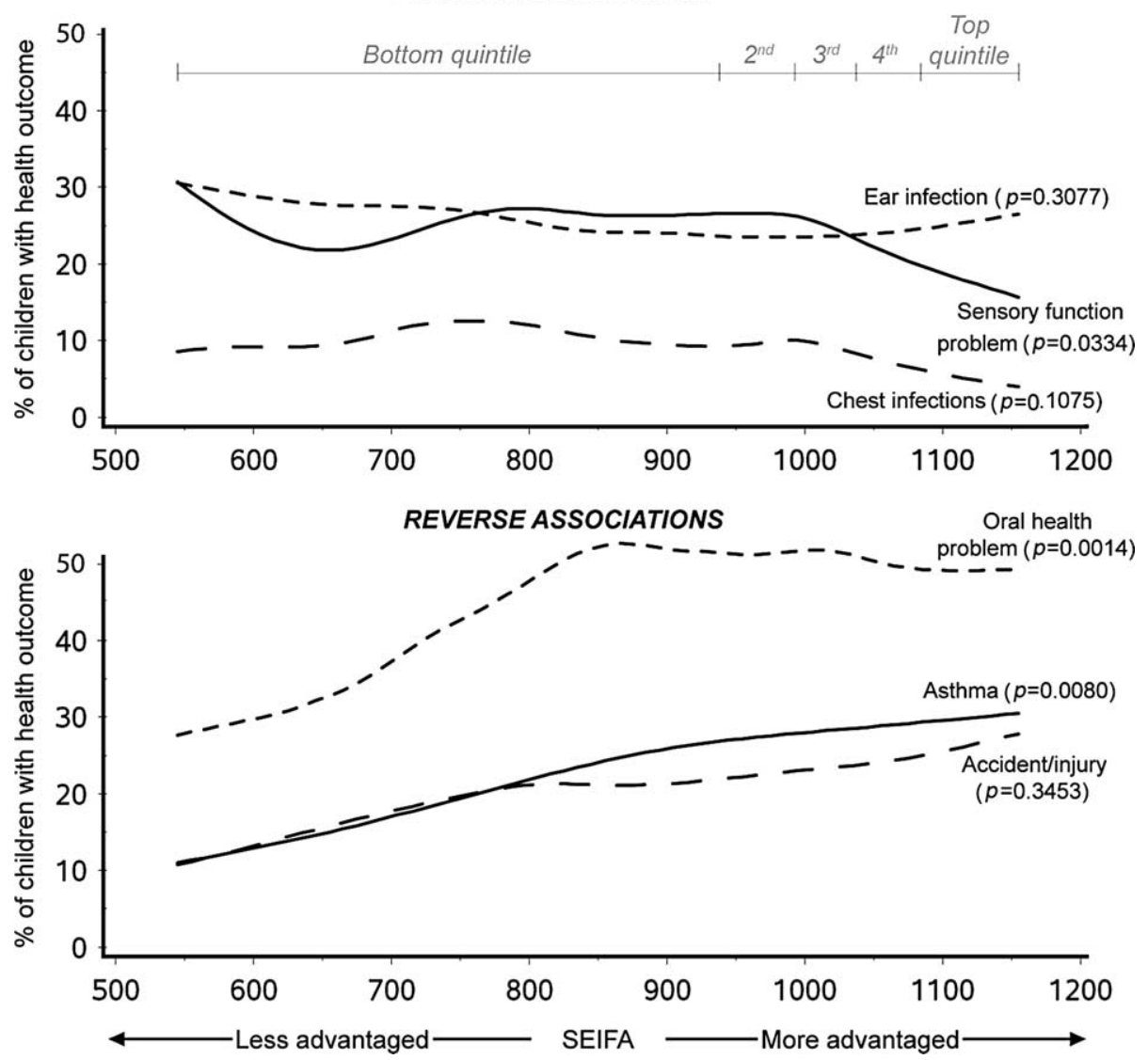

Figure 1. Pattern of association between SEIFA and various physical health outcomes for Western Australian Aboriginal children, 2000-2002.

Note: Data for asthma, and ear and chest infections refer to $0-17$-year-olds; all other data refer to 4-17-year-olds. Results are derived using Generalized Additive Models, adjusting for age and sex, and accounting for survey weights.

\section{Discussion}

We examined six health outcomes across eight SES variables and found that half of the associations exhibited a statistically significant socio-economic disparity in health, although the direction, shape and magnitude of associations differed. While these findings suggest that socio-economic factors shape the physical health of Aboriginal children to some degree, the diversity of results implies that other factors are likely to play a significant role in the pattern of these health outcomes.

It is not surprising to observe inconsistent patterns across health outcomes, as each outcome has a unique and complex causal pathway and is likely to interact with socio-economic factors in different ways and at different points along the pathway (Marmot and Wilkinson 2006). For example, education is known to influence the aetiology of many health outcomes, partly through pathways involving greater access to material resources and health care (Reynolds and Ross 1998). However, in an 


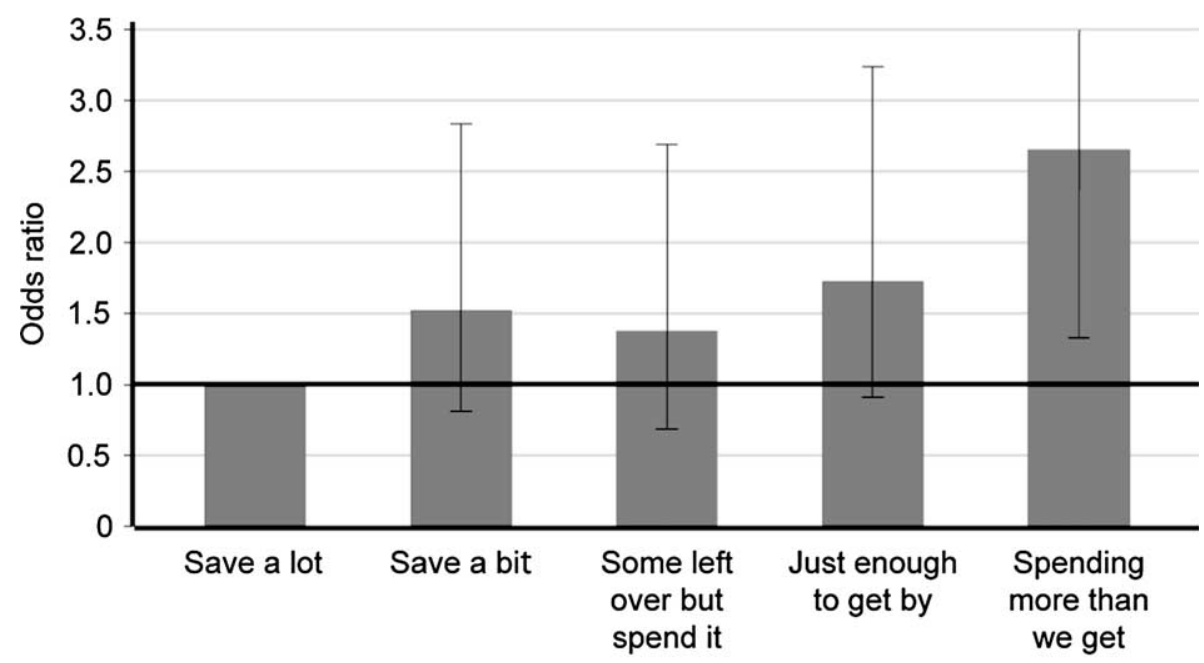

Family financial strain

Figure 2. Relative odds of recurring chest infections by categories of family financial strain, Western Australian Aboriginal children aged 0-17 years, 2000-2002.

Note: Odds ratios are derived from logistic regression models, adjusted for age and sex and accounting for survey weights.

Aboriginal context, the pathway from education to wealth creation and health could conceivably be weakened by the direct and indirect effects of discrimination and racism. For example, the persistent marginalisation of Aboriginal peoples can limit developmental opportunities for children. This, in turn, can inhibit the attainment of skills and abilities that can be drawn upon for the benefit of health at each level of SES, and this may alter the SES-health relationship in Indigenous contexts.

\section{Positive gradients}

Despite the diversity across outcomes, the results for ear infections, recurring chest infections and sensory function problems were generally consistent with a positive socio-economic gradient. This is the prevailing pattern in the wider literature, where lower parental SES is generally linked to poorer child health outcomes (Adler and Stewart 2010), including conditions related to the physical health outcomes discussed here (Cohen 1999, Chen and Matthews 2002). There are few studies that examine SES-health relationships among Indigenous children, and none are directly comparable with this study. Chi et al. reported a positive but statistically insignificant association between helicobacter pylori infection and both parental education and income among Aboriginal children in Taiwan (Chi et al. 2009). Studies of adult Aboriginal populations in Australia confirm that there are positive gradients with aspects of physical health, including end-stage renal disease, diabetes and cardiovascular disease (Cass et al. 2002, Cunningham et al. 2008, Cunningham 2010a, 2010b). The results of these studies may not be generalisable to Aboriginal child populations, given the conflicting evidence on the strength of gradients by age (Bartley et al. 1997). While childhood has been characterised as a period of relatively 
Table 4. Correlation between SES variables used in the study. ${ }^{\mathrm{a}}$

\begin{tabular}{|c|c|c|c|c|c|}
\hline & Education (secondary carer) & Family financial strain & Housing quality & SEIFA $^{b}$ & IRISEO $^{c}$ \\
\hline Education (primary carer) & $0.47(p<0.001)$ & $0.30(p<0.001)$ & $0.38(p<0.001)$ & $0.17(p<0.001)$ & $0.17(p<0.001)$ \\
\hline Education (secondary carer) & & $0.24(p=0.017)$ & $0.21(p=0.041)$ & $0.19(p<0.001)$ & $0.21(p<0.001)$ \\
\hline Family financial strain & & & $0.18(p=0.005)$ & $0.02(p=0.779)$ & $0.08(p=0.010)$ \\
\hline Housing quality & & & & $0.29(p<0.001)$ & $0.26(p<0.001)$ \\
\hline SEIFA $^{\mathrm{b}}$ & & & & & $0.37(p<0.001)$ \\
\hline
\end{tabular}

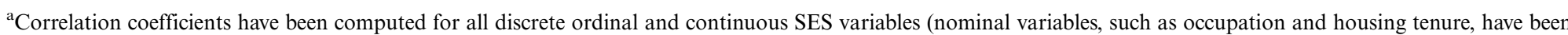
omitted). Observations with missing values are excluded from all calculations. Coefficients are estimated using linear and logistic regression models, and adjusted to account for the complex survey design and survey weights.

${ }^{\mathrm{b}}$ Customised version of the index of relative socio-economic disadvantage that forms part of the Australian Bureau of Statistics' Socioeconomic Index for Areas (SEIFA) product.

cBiddle's Index of Relative Indigenous Socioeconomic Outcomes. The index was derived using the characteristics of Indigenous persons only. 


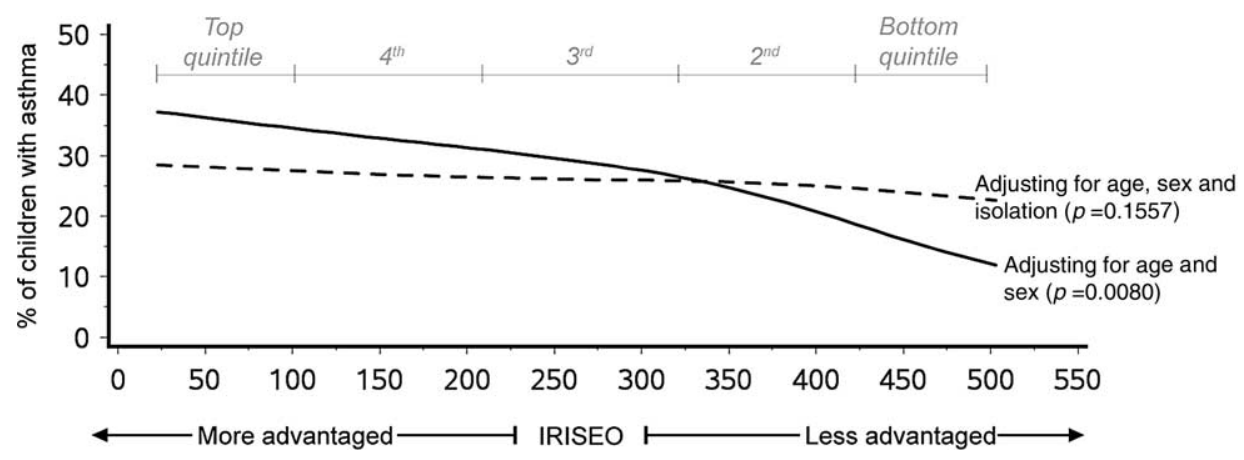

Figure 3. The impact of relative geographic isolation on the pattern of association between area-level socio-economic disadvantage (IRISEO) and asthma for Aboriginal children aged 0 17 years, 2000-2002.

Note: Results are derived using a Generalized Additive Model, adjusting for age and sex, and accounting for survey weights.

shallow gradients, life course patterns are likely to vary depending on the choice of health and SES indicators and population context (Adler and Stewart 2010).

\section{Reverse gradients}

However, better health was not always associated with higher SES, particularly for asthma, accidents/injuries and oral health. The reverse associations found here, while curious, are not necessarily surprising results. This pattern has been observed in mainstream populations for each of these three outcomes (Scheidt et al. 1995, Goh et al. 1996, Dugmore and Rock 2005). Reverse associations between SES and health in mainstream populations have been variously attributed to measurement anomalies (e.g., labelling and reporting bias) or methodological concerns (e.g., no consideration of pertinent mediators such as access to health services, quality of health care and environmental conditions or the impact of SES mobility), and these issues may have relevance to our findings. While our findings for asthma contrast those found for Aboriginal adults (Cunningham 2010c), they are plausibly explained by the hygiene hypothesis, on the assumption that lower SES is linked to greater infectious challenge in early life (Shankardass et al. 2007). The associations with accidents and injuries may reflect greater availability of recreational activities and facilities for children living in more affluent areas or in families with greater material resources (Scheidt et al. 1995). Further, our measure of childhood accidents/injuries includes hospitalisation events which are influenced by better access to hospitals and more responsive care-seeking behaviours, all of which are typically associated with higher SES (Agency for Healthcare Research and Quality 2003). While the significance of these issues cannot be adequately empirically tested using these data, they remain pertinent theories for further exploration.

Our findings for oral health in Western Australian Aboriginal children are counter to the marked positive socioeconomic gradients found among Aboriginal and Torres Strait Islander children in the Northern Territory (Jamieson et al. 2006). This discrepancy may be attributable to differences in sample characteristics, data collection methods or the measurement of oral health between the two studies. In our 
study, a composite binary indicator was created from carer responses to four questions (ever had holes in teeth, teeth removed, fillings, or sore/bleeding gums), whereas Jamieson et al. (2006) analysed the number of decayed, missing and filled teeth in the deciduous dentition (dmft) and in the permanent dentition (DMFT) of children based on dental examinations by a government-funded school dental service. Our carer-reported measure of dental problems may be a greater reflection of dental services access and utilisation than dental problems per se. If so, then our findings would suggest that dental services are more accessible (and possibly affordable) to Aboriginal children living in areas of higher relative advantage.

\section{Conventional and alternative measures of SES}

The findings highlighted that a number of SES constructs are associated with child physical health, including those that measure the SES characteristics of carers, families, households and neighbourhoods. The largest disparities in health were observed for area-level SES indicators, which may relate to the greater importance that Aboriginal peoples place on social connections with family and community than to individuals.

The study confirms that the physical health of Indigenous children can differ by conventional measures of SES, although outcomes were more sensitive to primary than secondary carer education and to employment status than occupation. This is in accordance with a substantial body of literature that demonstrates that the education of the mother is a more proximate determinant of child health and development than that of the father (Cochrane et al. 1982). More broadly, the diversity of our results could imply that conventional SES measures alone are inadequate for explaining variations in health outcomes in Indigenous contexts. Standard indicators of educational attainment typically ignore knowledge that is valued in Indigenous society (that has an impact on status) but acquired outside of Western education systems, while most income measures do not properly account for the nature of sharing of economic resources that can occur between extended members of Indigenous families (Hunter et al. 2003).

\section{Effects of geographic isolation}

We demonstrated that geographic isolation does not explain the relationship between SES and Aboriginal child physical health outcomes (with the partial exception of the relationship with an area-based IRISEO). This is somewhat surprising because many of the factors that impact on population health are unevenly distributed across areas of geographic isolation. For example, there tends to be fewer health care services in more isolated areas. This is particularly pertinent for Aboriginal peoples who, despite predominantly living in urban settings, are far more likely than non-Aboriginal Australians to live in remote and isolated areas. The finding that geographical isolation partially explains away the association between IRISEO and child health outcomes confirms a common belief that Aboriginal peoples living in isolated areas are more disadvantaged. Notwithstanding, they also suggest that the area-level SES characteristics of both the Aboriginal and total population have an independent effect on the physical outcomes of Aboriginal children. 


\section{Limitations of this study}

The main strength of this study is that it draws upon a representative data-set that was collected using robust and culturally appropriate methods, and that it employs rigorous analytical methods. The limitations primarily relate to difficulties in measuring SES and health and a reliance on cross-sectional data which limits an assessment of the causal relationships between SES and health. Our findings are based on self-reported, or subjective, measures of health, which are inherently open to issues of bias, particularly among socially disadvantaged people who may underreport or understate poor health outcomes (Sen 2002). This can give rise to a flatter health gradient when compared with results that rely on objective assessments of health (Matthews et al. 2010). This may be exacerbated by the reliance on carer perceptions of child health status - as a carer's views may not accord with that of a medical expert or the child. However, we believe that the use of Aboriginal interviewers, including Aboriginal health workers where possible, has minimised misclassification error. Future research will benefit from collecting information on both objective and self-reported health measures and comparing the patterns of their association with SES.

The measurement of accidents and injuries was restricted to the narrow set of available variables from the survey. The exclusion of a wider range of adverse events, including those resulting in hospitalisation, may have influenced the observed relationships. Sensory function problems were assessed using three different, albeit partly overlapping, limitations (vision, hearing and speech problems). While the prevalence of these limitations was too low to enable separate analysis, their aggregation may have obscured a different SES patterning of health for each limitation.

Access and use of health services is likely to affect a number of the study outcomes. Robust objective measures of health service access were not available in this study; carers were asked about satisfaction with access to services but this is not a substitute for access. We have adjusted our regression model results for geographic isolation (using the LORI measure) and this partly, but not adequately, accounts for the fact that services are less accessible in more remote areas.

Socioeconomic status, like health outcomes, may have been incorrectly reported by some survey participants. Some participants may have considered expenditure on wealth creation initiatives (e.g., home loan repayments) as a family financial strain. If this interpretation was consistently applied by participants then financial strain estimates will be overstated and potentially lessen the strength of health gradients for this SES measure. Further, the overrepresentation of Aboriginal children in the lower levels of all SES constructs used in the study has reduced the statistical power for comparing child health outcomes across SES levels, and this may have obscured the nature of the SES-health relationship in some instances.

\section{Future directions}

There is a critical need for future research to identify pathways from SES to Aboriginal child health. Our understanding of these pathways is likely to be enhanced by examining a range of factors that relate specifically to Indigenous 
circumstances and culture in the past and present day, such as the high levels of stress that Indigenous peoples are typically exposed to in daily life, racism and loss of cultural continuity. These should be explored in conjunction with known determinants of specific child health outcomes.

Most of the SES indicators used in this study are only relatively weakly correlated among themselves and, consequently, continue to have an independent effect on physical health when analysed collectively. This suggests that socio-economic characteristics in different domains and at multiple levels have an independent influence on Aboriginal health, and addressing them has the potential to significantly improve the health status of, and reduce the health inequalities within, Aboriginal populations. Strategies that attempt to reduce social inequalities in health within Aboriginal populations need to be multifaceted, and acknowledge that the development of human capital and supporting the household and wider community environment are all important.

\section{Key messages}

- There are significant socio-economic disparities in the physical health outcomes of Indigenous children in Australia

- The direction, shape and magnitude of these socio-economic disparities varies considerably, by both socio-economic measure and health outcome

- The socio-economic characteristics of carers, households and neighbourhoods all have an influence on the physical health of Indigenous children, with arealevel measures of SES having the strongest impact.

\section{Acknowledgements}

We wish to thank Professor David Lawrence for advice on statistical methods. Carrington Shepherd is financially supported by a Sidney Myer Health Scholarship.

\section{References}

Adler, N.E., 1993. Socioeconomic inequalities in health: no easy solution. Journal of American Medical Association, 269, 3140.

Adler, N.E., 1999. Socioeconomic status and health in industrial nations: social, psychological, and biological pathways. New York: New York Academy of Sciences.

Adler, N.E. and Rehkopf, D.H., 2008. U.S. disparities in health: descriptions, causes, and mechanisms. Annual Review of Public Health, 29, 35-52.

Adler, N.E. and Stewart, J., 2010. Health disparities across the lifespan: meaning, methods, and mechanisms. Annals of the New York Academy of Sciences, 1186, 5-23.

Agency for Healthcare Research and Quality, 2003. National healthcare disparities report. Rockville, Maryland: US Department of Health \& Human Services.

Alessandri, L.M., et al., 2001. Perinatal and postneonatal mortality among Indigenous and non-indigenous infants born in Western Australia, 1980-1998. Medical Journal of Australia, $175,185-189$.

Altman, J.C., 2000. The economic status of Indigenous Australians. Canberra: Centre for Aboriginal Economic Policy Research \& The Australian National University.

Anderson, I., 2007. Understanding the processes. In: B. Carson, T. Dunbar, R.D. Chenhall, and R. Bailie, eds. Social determinants of indigenous health. Sydney: Allen \& Unwin, 21-40. 
Anderson, I., et al., 2006. Indigenous health in Australia, New Zealand, and the Pacific. Lancet, 367, 1775-1785.

Australian Bureau of Statistics, 1998. Information paper: 1996 census of population and housing. Socioeconomic index for areas. Canberra: ABS. Catalogue no. 2039.0.

Australian Bureau of Statistics, 2004. National Aboriginal and Torres Strait Islander social survey, 2002. Canberra: Australian Bureau of Statistics.

Australian Bureau of Statistics, 2007. ABS directions in Aboriginal and Torres Strait Islander statistics. Canberra: Australian Bureau of Statistics.

Australian Bureau of Statistics and Australian Institute of Health and Welfare, 2008. The health and welfare of Australia's Aboriginal and Torres Strait Islander peoples. Canberra: Australian Bureau of Statistics.

Australian Institute of Health and Welfare, 2009. A picture of Australia's children 2009. Canberra: Australian Institute of Health and Welfare.

Australian Institute of Health and Welfare, 2011. The health and welfare of Australia's Aboriginal and Torres Strait Islander people. Canberra: Australian Institute of Health and Welfare.

Bailie, R.S. and Runcie, M.J., 2001. Household infrastructure in Aboriginal communities and the implications for health improvement. Medical Journal of Australia, 175, 363-366.

Bartley, M., Blane, D., and Montgomery, S., 1997. Socioeconomic determinants of healthhealth and the life course: why safety nets matter. British Medical Journal, 314, 1194-1196.

Biddle, N., 2009. Ranking regions: revisiting an index of relative indigenous socioeconomic outcomes. Canberra, CAEPR Working Paper No. 50/2009.

Blair, E., 1996. Why do Aboriginal neonates weigh less? Determinants of birthweight for gestation. Journal of Paediatrics and Child Health, 32, 498-503.

Case, A., Lubotsky, D., and Paxson, C., 2002. Economic status and health in childhood: the origins of the gradient. American Economic Review, 92, 1308-1334.

Cass, A., et al., 2002. End-stage renal disease in indigenous Australians: a disease of disadvantage. Ethnicity and Disease, 12, 373-378.

Cass, A., et al., 2004. Exploring the pathways leading from disadvantage to end-stage renal disease for Indigenous Australians. Social Science \& Medicine, 58, 767-785.

Chen, E., Martin, A.D., and Matthews, K.A., 2005. Socioeconomic status and health: do gradients differ within childhood and adolescence? Social Science and Medicine, 62, 2161-2170.

Chen, E. and Matthews, K.A., 2002. Socioeconomic differences in children's health: how and why do these relationships change with age? Psychological Bulletin, 128, 295-329.

Chi, H., et al., 2009. Prevalence of Helicobacter pylori infection in high-school students on Lanyu Island, Taiwan: risk factor analysis and effect on growth. Journal of the Formosan Medical Association, 108, 929-936.

Cochrane, S.H., Leslie, J., and Ohara, D.J., 1982. Parental education and child health intracountry evidence. Health Policy and Education, 2, 213-250.

Cohen, S., 1999. Social status and susceptibility to respiratory infections. Annals of the New York Academy of Sciences, 896, 246-253.

Cunningham, J., 2010a. Socio-economic gradients in self-reported diabetes for Indigenous and non-Indigenous Australians aged 18-64. Australian and New Zealand Journal of Public Health, 34, S18-S24.

Cunningham, J., 2010b. Socioeconomic disparities in self-reported cardiovascular disease for Indigenous and non-Indigenous Australian adults: analysis of national survey data. Population Health Metrics, 8, 31.

Cunningham, J., 2010c. Socioeconomic status and self-reported asthma in Indigenous and non-Indigenous Australian adults aged 18-64 years: analysis of national survey data. International Journal for Equity in Health, 9, 18.

Cunningham, J., et al., 2008. Socioeconomic status and diabetes among urban Indigenous Australians aged 15-64 years in the DRUID study. Ethnicity \& Health, 13, $23-37$.

Cunningham, J., Sibthorpe, B., and Anderson, I., 1997. Self-assessed health status, Indigenous Australians, 1994: occasional paper. Canberra: Australian Bureau of Statistics and National Centre for Epidemiology and Population Health. 
Dugmore, C.R. and Rock, W.P., 2005. The effect of socio-economic status and ethnicity on the comparative oral health of Asian and White Caucasian 12-year-old children. Community Dental Health, 22, 162-169.

Freemantle, C.J., et al., 2006. Patterns, trends, and increasing disparities in mortality for Aboriginal and non-Aboriginal infants born in Western Australia, 1980-2001: population database study. Lancet, 367, 1758-1766.

Glover, J., Tennant, S., and Page, A., 2004. The impact of socioeconomic status and geographic location on Indigenous mortality in Australia, 1997-99. Adelaide: Public Health Information Development Unit \& University of Adelaide.

Goh, D.Y.T., et al., 1996. Prevalence and severity of asthma, rhinitis, and eczema in Singapore schoolchildren. Archives of Disease in Childhood, 74, 131-135.

Hastie, T.J. and Tibshirani, R.J., 1990. Generalised additive models. New York: Chapman and Hall.

Human Rights and Equal Opportunity Commission, 1997. Bringing them home: national inquiry into the separation of Aboriginal and Torres Strait Islander children from their families. Canberra: Human Rights and Equal Opportunity Commission.

Hunter, E., 1993. Aboriginal health and history: power and prejudice in remote Australia. Cambridge: Cambridge University Press.

Hunter, B., 1999. Three nations, not one: indigenous and other Australian poverty. Canberra: Centre for Aboriginal Economic Policy Research \& The Australian National University, $1 / 1999$.

Hunter, B., 2000. Social exclusion, social capital, and Indigenous Australians: measuring the social costs of unemployment. Canberra: Centre for Aboriginal Economic Policy Research \& The Australian National University.

Hunter, B., Kennedy, S., and Smith, D., 2003. Household composition, equivalence scales and the reliability of income distributions: some evidence for indigenous and other Australians. Economic Record, 79, 70-83.

Jamieson, L.M., Armfield, J.M., and Roberts-Thomson, K.F., 2006. Oral health inequalities among indigenous and nonindigenous children in the Northern Territory of Australia. Community Dentistry and Oral Epidemiology, 34, 267-276.

Jones, H.L., 1974. Jackknife estimation of functions of stratum means. Biometrika, 61, 343-348.

Keating, D.P. and Hertzman, C., 1999. Modernity's paradox. In: D.P. Keating and C. Hertzman, eds. Developmental health and the wealth of nations: social, biological, and educational dynamics. New York: The Guildford Press, 1-17.

Leeds, K.L., et al., 2007. Indigenous mothers and their babies, Australia 2001-2004. Canberra, AIHW. Cat. no. PER 38. Perinatal statistics series no. 19.

Macintyre, S., 1994. Understanding the social patterning of health: the role of the social sciences. Journal of Public Health, 16, 53-59.

Marmot, M.G. and Wilkinson, R.G., 2006. Social determinants of health. 2nd ed. Oxford: Oxford University Press.

Matthews, K.A., Gallo, L.C., and Taylor, S.E., 2010. Are psychosocial factors mediators of socioeconomic status and health connections? Annals of the New York Academy of Sciences, $1186,146-173$.

Morrissey, M.J., 2003. Poverty and indigenous health. Annual Review of Health Social Sciences, 12, 17-30.

Mueller, C.W. and Parcel, T.L., 1981. Measures of socioeconomic-status - alternatives and recommendations. Child Development, 52, 13-30.

Oddy, W.H., et al., 2008. The association of infant feeding with parent-reported infections and hospitalisations in the West Australian Aboriginal Child Health Survey. Australian and New Zealand Journal of Public Health, 32, 207-215.

Paradies, Y., Harris, R., and Anderson, I., 2008. The impact of racism on indigenous health in Australia and Aotearoa: towards a research agenda. Darwin, Discussion Paper No. 4.

Pfeffermann, D., et al., 1998. Weighting for unequal selection probabilities in multilevel models. Journal of the Royal Statistical Society: Series B (Statistical Methodology), 60, $23-40$. 
Reynolds, J.R. and Ross, C.E., 1998. Social stratification and health: education's benefit beyond economic status and social origins. Social Problems, 45, 221-247.

Saggers, S. and Gray, D., 1991. Aboriginal health and society: the traditional and contemporary aboriginal struggle for better health. North Sydney: Allen \& Unwin.

Scheidt, P.C., et al., 1995. The epidemiology of nonfatal injuries among US children and youth. American Journal of Public Health, 85, 932-938.

Sen, A., 2002. Health: perception versus observation. British Medical Journal, 324, 860-861.

Shankardass, K., et al., 2007. The association between contextual socioeconomic factors and prevalent asthma in a cohort of Southern California school children. Social Science and Medicine, 65, 1792-1806.

Shavers, V.L., 2007. Measurement of socioeconomic status in health disparities research. Journal of the National Medical Association, 99, 1013-1023.

Shaw, M., 2004. Housing and public health. Annual Review of Public Health, 25, 397-418.

Silburn, S.R., et al., 2006. The Western Australian Aboriginal Child Health Survey: strengthening the capacity of aboriginal children, families and communities. Perth: Telethon Institute for Child Health Research.

Steering Committee for the Review of Government Service Provision (Scrgsp), 2009. Overcoming indigenous disadvantage: key indicators 2009. Canberra: Productivity Commission.

Taylor, J., 2008. Indigenous peoples and indicators of well-being: Australian perspectives on United Nations global frameworks. Social Indicators Research, 87, 111-126.

Titmuss, A.T., Harris, E., and Comino, E.J., 2008. The roles of socioeconomic status and aboriginality in birth outcomes at an urban hospital. Medical Journal of Australia, 189, 495-498.

Wolter, K.M., 1985. Introduction to variance estimation. New York: Springer Verlag.

Zubrick, S.R., et al., 2004. Western Australian Aboriginal Child Health Survey: the health of aboriginal children and young people. Perth: Telethon Institute for Child Health Research.

Zubrick, S.R., et al., 2005. The Western Australian Aboriginal Child Health Survey: the social and emotional wellbeing of aboriginal children and young people. Perth: Telethon Institute for Child Health Research. 